\title{
Mantle Cell Lymphoma Diagnosed by Conjunctival Salmon-Pink Lesion Biopsy
}

\author{
Toshihiko Matsuo, ${ }^{1)}$ Kouichi Ichimura, ${ }^{2)}$ and Shiro Kubonishi ${ }^{3)}$
}

Conjunctival lesions are rarely seen in mantle cell lymphoma. Here, we report a patient who developed bilateral conjunctival lesions in the course of chronic lymphocytic leukemia as an initial diagnosis, resulting in the final diagnosis of mantle cell lymphoma by conjunctival biopsy. A 66-year-old man developed conjunctival salmon-pink lesions on both sides in the 1.5-year course of chronic lymphocytic leukemia. He also had irregularly shaped masses with low tissue density in the orbital apex on both sides. Bilateral conjunctival biopsy showed subepithelial infiltration with lymphoid cells, positive for CD20, CD5, and cyclin D1, but negative for $\mathrm{CD} 3, \mathrm{CD} 10$, and CD23. Immunohistochemical restaining of the previous bone marrow biopsy specimen demonstrated lymphoid cells positive for cyclin D1, confirming the diagnosis of mantle cell lymphoma with leukemic presentation. As the case presenting stage IV lymphoma with systemic lymphadenopathy, he underwent 3 courses of combination chemotherapy with fludarabine and cyclophosphamide, and then 6 courses of bendamustine with rituximab, leading to complete remission for the following 3 years. In conclusion, mantle cell lymphoma should be included in the differential diagnosis of conjunctival salmon-pink lesions. 〔J Clin Exp Hematop 54(2) : 143-147, 2014〕

Keywords: mantle cell lymphoma, conjunctiva, conjunctival biopsy, leukemia, salmon-pink lesion

\section{INTRODUCTION}

Lymphoma involves ocular adnexa, which consists mainly of lacrimal glands and sacs, extraocular muscles, eyelids, and conjunctiva. Ocular adnexal lymphoma predominantly presents as an orbital mass. Mantle cell lymphoma is generally a well-recognized pathological type in the list of ocular adnexal lymphomas. ${ }^{1}$ However, conjunctival involvement with lymphoma in general, and more specifically with mantle cell lymphoma, is relatively rare.

Conjunctival salmon-pink lesions are a hallmark of conjunctival infiltration with lymphoid cells. The primary lymphoma, occurring in the conjunctiva, is predominantly extranodal marginal zone B-cell lymphoma of the mucosa-associated lymphoid tissue (MALT), called MALT lymphoma. ${ }^{2-7}$ The

Received: May 6, 2014

Revised : June 2, 2014

Accepted: July 9, 2014

Departments of ${ }^{1)}$ Ophthalmology and ${ }^{2}$ Pathology, Okayama University Hospital and Graduate School of Medicine, Dentistry, and Pharmaceutical Sciences, Okayama City, Japan

${ }^{3}$ Hematology/Oncology, National Hospital Organization Okayama Medical Center, Okayama City, Japan

Corresponding author: Toshihiko Matsuo, M.D., Ph.D., Department of Ophthalmology, Okayama University Medical School and Graduate School of Medicine, Dentistry, and Pharmaceutical Sciences, 2-5-1 Shikata-cho, Okayama City 700-8558, Japan

E-mail: matsuot@cc.okayama-u.ac.jp other rare types of lymphoma involving the conjunctiva that have been reported so far are T-cell lymphoma, ${ }^{8}$ Burkitt lymphoma, ${ }^{9}$ mantle cell lymphoma, ${ }^{10-12}$ and blastic plasmacytoid dendritic cell neoplasm. ${ }^{13}$ The conjunctival lesions could also be caused by benign lymphoid hyperplasia ${ }^{14-16}$ and leukemic infiltration. ${ }^{17-21}$

In this study, we report a patient who developed bilateral conjunctival lesions in the course of chronic lymphocytic leukemia as an initial diagnosis. Conjunctival biopsy demonstrated mantle cell lymphoma, which was also supported by immunohistochemical restaining of the previous bone marrow biopsy specimen.

\section{CASE REPORT}

A 66-year-old man noticed blurred vision in both eyes associated with bilateral buccal pain 10 days previously, bilateral lower lid swelling 7 days previously, and bilateral lower lid induration 3 days previously. Upon referral from a hematologist in October 2010, he showed reddish lesions in the lower conjunctival fornix on both sides (Fig. 1). The bestcorrected visual acuity was 0.5 in the right eye and 0.7 in the left eye. The intraocular pressure in both eyes was $20 \mathrm{mmHg}$. $\mathrm{He}$ had clear media and normal fundi in both eyes. Computed tomographic scan disclosed ill-defined lesions with low tissue density at the orbital apex along the optic nerve in bilateral orbit (Fig. 1). 

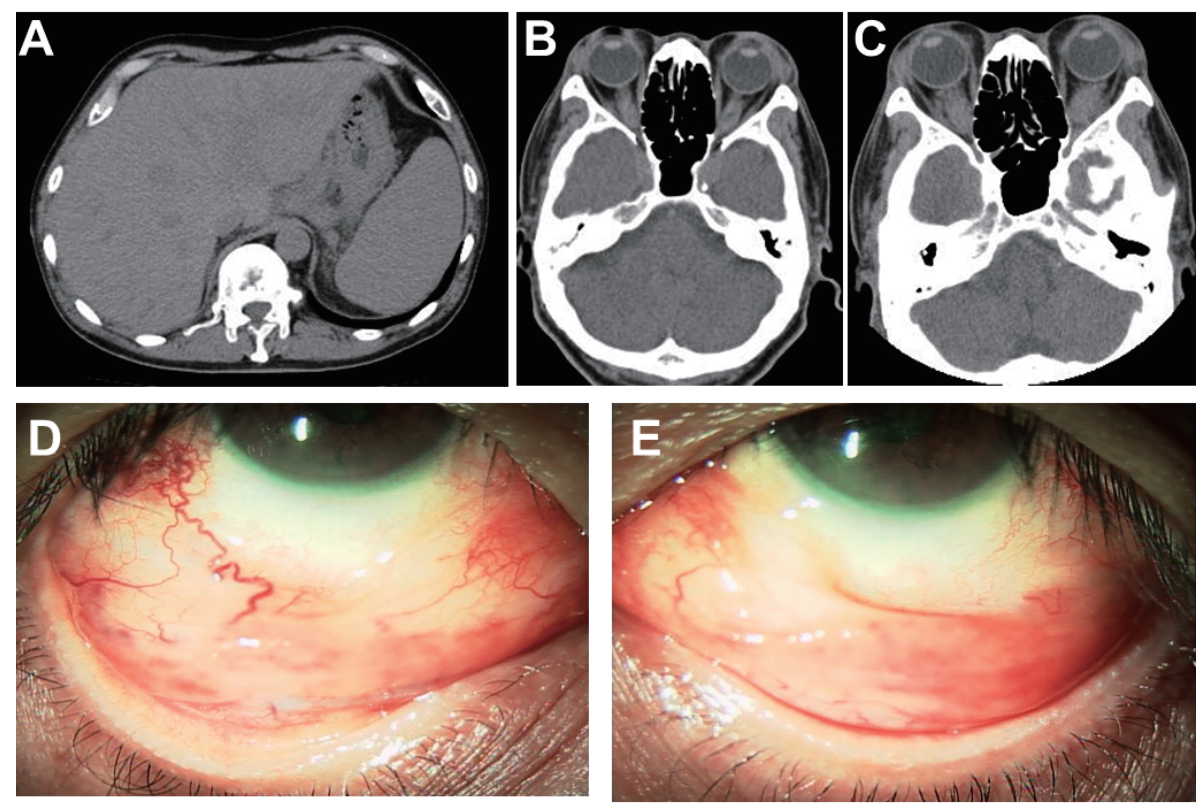

Fig. 1. A 66-year-old man. Hepatosplenomegaly in January $2010(1 A)$, bilateral orbital apex lesions in June $2010(1 B)$ and in October 2010 (IC) on computed tomographic scans. Right $(1 D)$ and left $(I E)$ conjunctival lower fornix lesions in October 2010. Note more apparent orbital apex lesions in October $(1 C)$ than in June $(1 B)$.

He was identified as having leukocytosis by a health check in March 2009, and was diagnosed at another hospital with chronic lymphocytic leukemia, based on fluorescenceactivated cell sorting of the peripheral blood and immunohistochemistry of a bone marrow biopsy in April 2009. The abnormal bone marrow cells were positive for CD5, CD20, and CD23. About half a year later, in September 2009, he developed appendicitis, and the surgically excised specimen showed the infiltration of lymphocytes that were positive for CD5, CD20, and CD23.

Biopsy of conjunctival lesions on both sides in October 2010 showed subepithelial infiltration with small to mediumsized lymphoid cells that were positive for CD20, CD5, and cyclin D1, but negative for CD3, CD10, and CD23 on immunohistochemical staining, leading to the diagnosis of mantle cell lymphoma (Fig. 2). Immunohistochemical restaining of the previous bone marrow biopsy specimen demonstrated lymphoid cells positive for cyclin D1 (Fig. 3), confirming the diagnosis of mantle cell lymphoma with leukemic presentation.

Systemic lymphadenopathy was disclosed by computed tomography, which reaffirmed the stage IV mantle cell lymphoma. The patient underwent 3 courses of combination chemotherapy with fludarabine and cyclophosphamide from October 2010 to January 2011, leading to resolution of the orbital masses. As the lymphoma cells still remained in the blood, coupled with pleural effusion, he underwent 6 courses of bendamustine, combined with rituximab, as salvage che- motherapy for the progressive disease, resulting in complete remission in August 2011. He was followed for the following 3 years without any treatment.

\section{DISCUSSION}

A key for the diagnosis of mantle cell lymphoma is the nuclear overexpression of cyclin D1. ${ }^{22}$ In the present patient, conjunctival and orbital infiltration was initially considered as leukemic infiltration since the patient had been diagnosed with chronic lymphocytic leukemia based on bone marrow biopsy and fluorescence-activated cell sorter analysis. The bone marrow specimen was not stained for cyclin D1 immunohistochemically on that occasion. After mantle cell lymphoma was diagnosed by conjunctival biopsy, immunohistochemical restaining of the bone marrow biopsy specimen confirmed cyclin D1 overexpression in infiltrating lymphoid cells.

To the best of our knowledge, there have been three case reports describing conjunctival mantle cell lymphoma. ${ }^{10-12}$ These 3 patients showed unilateral conjunctival lesions: two patients with no systemic manifestations ${ }^{10,12}$ and one patient with hepatosplenomegaly and bone marrow involvement. ${ }^{11}$ In contrast, the present patient showed bilateral conjunctival lesions by mantle cell lymphoma. Mantle cell lymphoma is well known, although noted rarely, for leukemic presentation, ${ }^{22,23}$ which might have led to the bilateral conjunctival and orbital involvement in the present patient. 

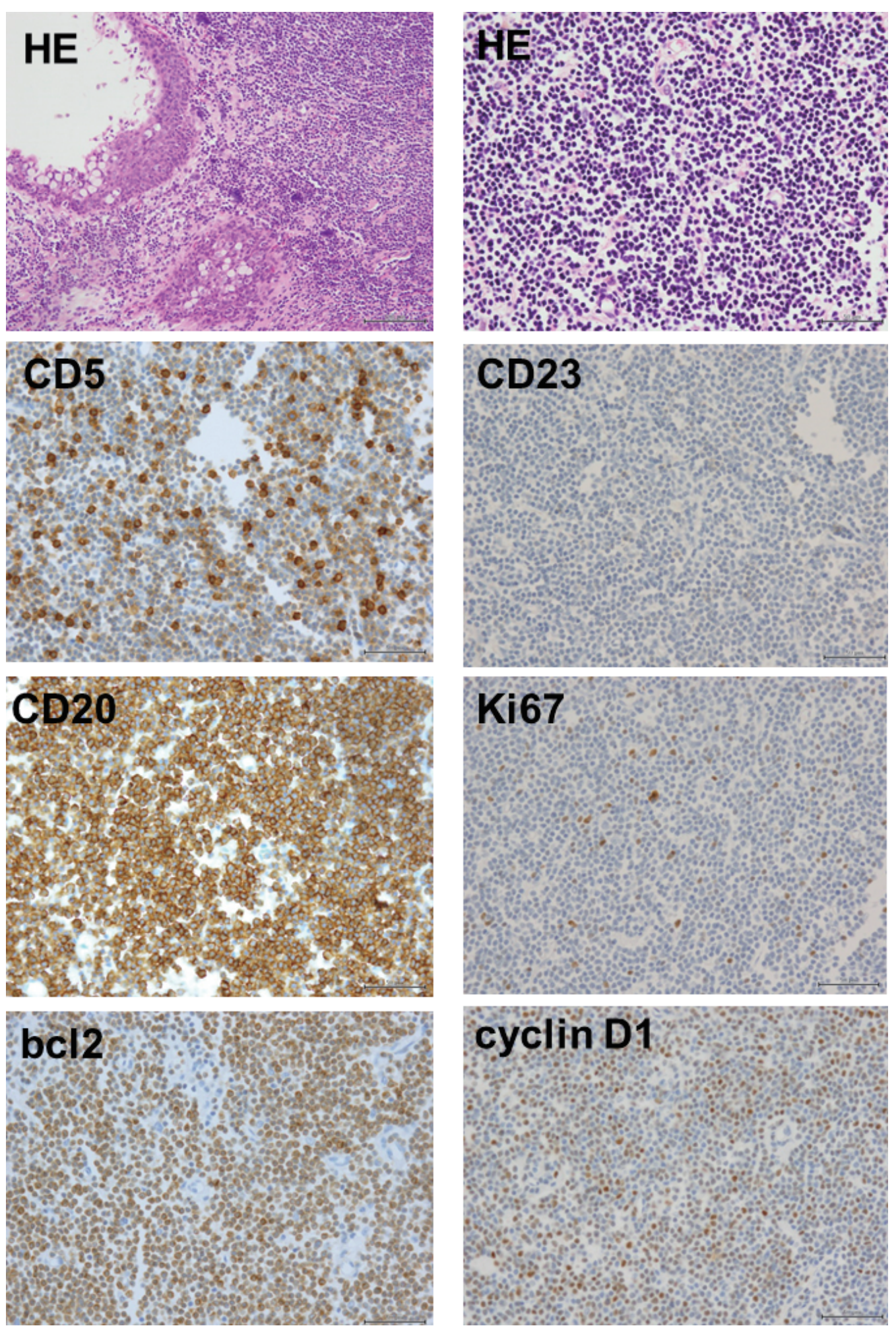

Fig. 2. Right conjunctival biopsy in a 66-year-old man in October 2010. Subepithelial infiltration with small to medium-sized lymphoid cells (H\&E stain), which are positive for CD5, CD20, bcl2, and cyclin D1, but negative for CD23. A small number of cells are positive for Ki67. Original magnification, $\times 40$ in all panels, except for $\times 20$ in the top left H\&E panel. Bar $=50 \mu \mathrm{m}$ in all panels, except for the top left HE panel where bar $=100 \mu \mathrm{m}$. 


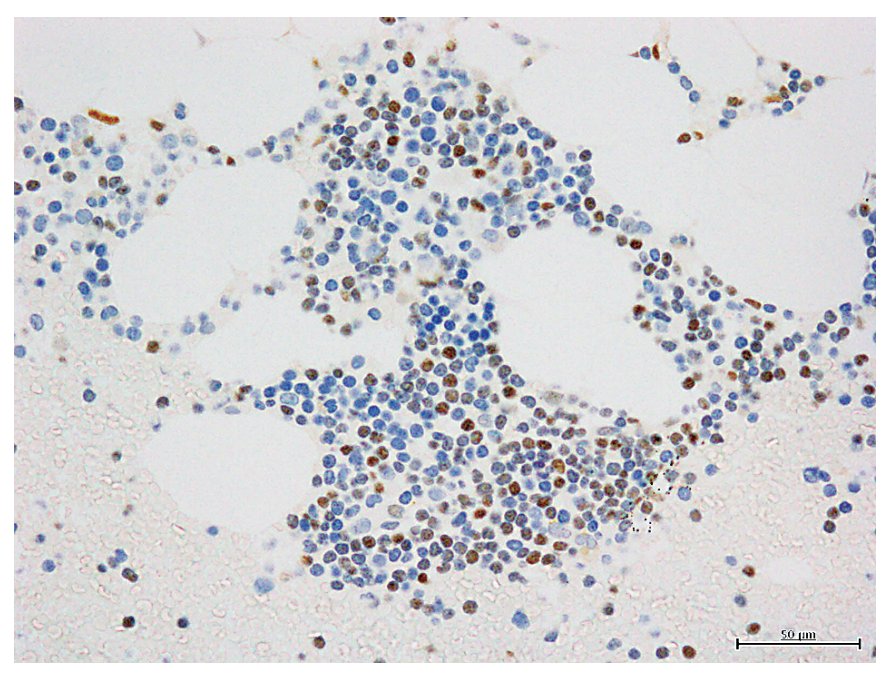

Fig. 3. Immunohistochemical restaining for cyclin D1 in October 2010 of the previous bone marrow biopsy specimen, obtained initially in April 2009. Note nuclear overexpression of cyclin D1. Original magnification, $\times 40$. Bar $=50 \mu \mathrm{m}$.

It should be noted that abnormal lymphoid cells in the initial bone marrow specimen and the following appendectomy specimen were positive for CD23, while lymphoid cells in the conjunctival biopsy specimen were negative for it. It is, in general, difficult to differentiate CD23-positive leukemic mantle cell lymphoma from chronic lymphocytic leukemia, as diagnosed upon the initial presentation of the present patient. Furthermore, lymphoma cells in the conjunctiva did not express CD23, which was detected by conjunctival biopsy, one year after the appendectomy specimen showed positive expression of CD23. The CD23 expression by lymphoma cells in mantle cell lymphoma would vary from tissue to tissue and also vary along the time course of the disease. ${ }^{24}$

In conclusion, mantle cell lymphoma should be considered in the list of differential diagnoses for conjunctival salmon-pink lesions. Conjunctival biopsy is recommended to confirm the preceding diagnosis or establish a new diagnosis.

\section{CONFLICT OF INTEREST}

The authors declare that they have no conflict of interest.

\section{REFERENCES}

1 Ferry JA, Fung CY, Zukerberg L, Lucarelli MJ, Hasserjian RP, et al.: Lymphoma of the ocular adnexa: A study of 353 cases. Am J Surg Pathol 31:170-184, 2007

2 Hardman-Lea S, Kerr-Muir M, Wotherspoon AC, Green WT, Morell A, et al.: Mucosa-associated lymphoid tissue lymphoma of the conjunctiva. Arch Ophthalmol 112:1207-1212, 1994

3 Wotherspoon AC, Hardman-Lea S, Isaacson PG: Mucosa- associated lymphoid tissue (MALT) in the human conjunctiva. J Pathol 174:33-37, 1994

4 Matsuo T, Yoshino T: Long-term follow-up results of observation or radiation for conjunctival malignant lymphoma. Ophthalmology 111:1233-1237, 2004

5 Matsuo T, Ichimura K, Yoshino T: Spontaneous regression of bilateral conjunctival extranodal marginal zone B-cell lymphoma of mucosa-associated lymphoid tissue. J Clin Exp Hematop 47:7981,2007

6 Matsuo T, Ichimura K, Okada H, Shinagawa K, Fukushima K, et al:: Clonal analysis of bilateral, recurrent, or systemically multifocal ocular adnexal lymphoma. J Clin Exp Hematop 50:27-38, 2010

7 Matsuo T, Ichimura K, Tanaka T, Kaji M: Conjunctival lymphoma can be detected by FDG PET. Clin Nucl Med 37:516-519, 2012

8 Al-Muammar A, Hodge WG, Farmer J: Conjunctival T-cell lymphoma: A clinicopathologic case report. Ophthalmology 113:459461, 2006

9 Weisenthal RW, Streeten BW, Dubansky AS, Hutchison RE, Pecora JL: Burkitt lymphoma presenting as a conjunctival mass. Ophthalmology 102:129-134, 1995

10 Aspiotis M, Gorezis S, Asproudis I, Tsanou E, Papadiotis E, et al.: Primary mantle cell lymphoma of the conjunctiva: a case report. Virchows Arch 449:472-475, 2006

11 Yoo SB, Kim YA, Jeon YK, Kim CW: CD5-undetected by immunohistochemistry, $\mathrm{t}(11 ; 14)(\mathrm{q} 13 ; \mathrm{q} 32)$-positive conjunctival mantle cell lymphoma: a case report. Pathol Res Pract 204:779-783, 2008

12 Khanlari M, Bagheri B, Vojdani R, Mohammadianpanah M, Paydar S, et al.: Conjunctival mass as an initial presentation of mantle cell lymphoma: case report. BMC Res Notes 5:671, 2012

13 Matsuo T, Ichimura K, Tanaka T, Morizane S, Iwatsuki K, et al.: Bilateral conjunctival lesions in blastic plasmacytoid dendritic cell neoplasm. J Clin Exp Hematop 51:49-55, 2011

14 Shields CL, Shields JA, Carvalho C, Rundle P, Smith AF: Conjunctival lymphoid tumors: clinical analysis of 117 cases and relationship to systemic lymphoma. Ophthalmology 108:979-984, 2001

15 Goto Y, Ohaki Y, Ibaraki N: A clinicopathologic case report of inflammatory pseudotumors involving the conjunctiva and lung. Jpn J Ophthalmol 48:573-577, 2004

16 Matsuo T, Ichimura K, Sato Y, Tanimoto Y, Kiura K, et al.: Immunoglobulin G4 (IgG4)-positive or -negative ocular adnexal benign lymphoid lesions in relation to systemic involvement. J Clin Exp Hematop 50:129-142, 2010

17 Font RL, Mackay B, Tang R: Acute monocytic leukemia recurring as bilateral perilimbal infiltrates. Immunohistochemical and ultrastructural confirmation. Ophthalmology 92:1681-1685, 1985

18 Lee DA, Su WPD: Acute myelomonocytic leukemia cutis presenting as a conjunctival lesion. Int J Dermatol 24:369-370, 1985

19 Tsumura T, Sakaguchi M, Shiotani N, Sugita A, Nakahara T: A case of acute myelomonocytic leukemia with subconjunctival tumor. Jpn J Ophthalmol 35:226-231, 1991

20 Cook BE Jr, Bartley GB: Acute lymphoblastic leukemia manifest- 
ing in an adult as a conjunctival mass. Am J Ophthalmol 124:104105, 1997

21 Lee SS, Robinson MR, Morris JC, Mirtsching BC, Shen D, et al:: Conjunctival involvement with T-cell prolymphocytic leukemia: report of a case and review of the literature. Surv Ophthalmol 49: 525-536, 2004

22 Jares $\mathrm{P}$, Campo E: Advances in the understanding of mantle cell lymphoma. Br J Haematol 142:149-165, 2008
23 Viswanatha DS, Foucar K, Berry BR, Gascoyne RD, Evans HL, et al:: Blastic mantle cell leukemia: an unusual presentation of blastic mantle cell lymphoma. Mod Pathol 13:825-833, 2000

24 Kelemen K, Peterson LC, Helenowski I, Goolsby CL, Javanovic $\mathrm{B}$, et al.: $\mathrm{CD} 23^{+}$mantle cell lymphoma: a clinical pathologic entity associated with superior outcome compared with CD23disease. Am J Clin Pathol 130:166-177, 2008 